\title{
A mixture of seaweed extracts and glycosaminoglycans from sea squirts inhibits a-MSH-induced melanogenesis in B16F10 melanoma cells
}

\author{
Lei Wang ${ }^{\dagger}$, Yong Ri Cui ${ }^{\dagger}$, Hye-Won Yang, Hyo Geun Lee, Ju-Young Ko ${ }^{*}$ and You-Jin Jeon ${ }^{*}$ (1)
}

\begin{abstract}
Background: In the present study, the skin-whitening effects of a marine-sourced mixture that includes a fucoidanrich extract of Undaria pinnatifida (UPEF), a phlorotannin-rich extract of Ecklonia cava (ECE), and glycosaminoglycans (GAGs) from sea squirt skin were investigated.

Methods: The whitening effects of the mixture and its components were evaluated by measuring the inhibition of mushroom tyrosinase and melanin synthesis in alpha-melanocyte-stimulating hormone (a-MSH)-stimulated B16F10 melanoma cells.

Results: Each component alone markedly inhibited mushroom tyrosinase in a dose-dependent manner, and in aMSH-stimulated B16F10 cells, they inhibited melanin synthesis and were cytotoxic. However, the whitening effects of UPEF, ECE, and GAGs in combination were greater than those of each component alone. A mixture in the ratio of 4:5:1 (UEG-451) showed the strongest activity without cytotoxicity. Further study suggested that UEG-451 inhibits a-MSH-stimulated melanogenesis in B16F10 cells by downregulating tyrosinase and tyrosinase-related proteins, such as TRP-1 and TRP-2, via the inhibition of MITF expression.

Conclusions: These results suggest that mixing the different components at optimum ratios might be an effective way to improve their bioactivities and reduce toxicity and that UEG-451 possesses strong whitening effects that could be used in the cosmetic industry.
\end{abstract}

Keywords: Marine-sourced mixture, Seaweed extracts, Melanogenesis, Whitening

\section{Background}

Melanogenesis is the physiological process that produces melanin pigment, which contributes to skin and hair color (Gilchrest and Eller 1999; Kim et al. 2013). Melanin is the key pigment responsible for skin color in humans. Melanin may be overproduced in melasma, ultraviolet irradiation, and hyperpigmentation diseases. Recently, an increasing number of women desire whiter complexions, especially in Asian countries (Tengamnuay et al. 2006). Therefore, a naturally sourced compound, which not only downregulates melanogenesis but also

\footnotetext{
*Correspondence: herolegend@hanmail.net; youjinj@jejunu.ac.kr

${ }^{\dagger}$ Lei Wang and Yong Ri Cui contributed equally to this work.

Department of Marine Life Sciences, Jeju National University, Jeju 63243, Republic of Korea
}

has no side effects, may be a potential candidate from which to develop a therapeutic agent or cosmetic.

The ocean is an abundant source of both biologically and chemically diverse species. Because of the special environment, marine organisms, including plants, animals, and microorganisms, produce unique metabolites (Kijjoa and Sawangwong 2004; Wang et al. 2016). These metabolites, such as phenolic compounds, carbohydrates, and peptides, possess antioxidant, anti-inflammatory, anticancer, anti-obesity, anti-hypertensive, and anti-diabetes bioactivities (Fernando et al. 2017; Kang et al. 2015; Kang et al. 2013; Kim et al. 2016; Kim et al. 2014; Ko et al. 2017; Lange et al. 2015; Lee et al. 2015; Lee et al. 2013; Oh et al. 2016; Samarakoon et al. 2014; Sanjeewa et al. 2016). Ahn et al. (2007) reported on the antioxidant activities of 
phlorotannins purified from Ecklonia cava, an edible brown alga (Ahn et al. 2007). Ko et al. (2016) purified peptides from flounder and investigated the anti-hypertensive activities of those peptides (Ko et al. 2016). Kim et al. (2014) isolated active compounds from marine bacteria and evaluated their bioactivities (Kim et al. 2014).

Undaria pinnatifida, an edible brown alga, is rich in polysaccharides, especially fucoidan. Park and Choi (2017) isolated different molecular weight fucoidan from $U$. pinnatifida and investigated their radical scavenging activities and inhibition of melanogenesis (Park and Choi 2017). E. cava is rich in phlorotannins, and we reported their antioxidant and melanogenesis inhibitory activities in a previous study (Ahn et al. 2007; Heo et al. 2009). Glycosaminoglycans (GAGs) are long, unbranched sulfated polysaccharides that possess strong antioxidant activity and possess the potential in cosmetic area (Campo et al. 2004). The objectives of the present study were to evaluate the whitening effects of a fucoidan-rich extract from $U$. pinnatifida, a phlorotannin-rich extract from E. cava, and GAGs from sea squirt skin. To improve the whitening effects and to reduce the cytotoxicities of these compounds, they were mixed in different ratios and tested to select the mixture that conferred optimal whitening without cytotoxicity.

\section{Materials and methods Chemicals and reagents}

Dimethyl sulfoxide (DMSO), 3-(4-5-dimethyl-2yl)-2-5diphynyltetrasolium bromide (MTT), mushroom tyrosinase, and alpha-melanocyte-stimulating hormone ( $\alpha-\mathrm{MSH})$ were purchased from Sigma Co. (St. Louis, MO, USA). Dulbecco's modified Eagle medium (DMEM), penicillin/ streptomycin, and fetal bovine serum (FBS) were purchased from Gibco BRL (Life Technologies, Burlington, ON, Canada). Antibodies against tyrosinase, tyrosinaserelated protein-1 and protein-2 (TRP-1 and TRP-2), and microphthalmia-associated transcription factor (MITF) were purchased from Santa Cruz Biotechnology (Santa Cruz, CA, USA). Anti-mouse and anti-rabbit IgG were purchased from Cell Signaling Technology (Beverly, MA, USA). All other chemicals were of analytical grade.

\section{Preparation of fucoidan-rich extract, phlorotanin-rich extract, and glycosaminoglycans}

$U$. pinnatifida was hydrolyzed with Celluclast. The polysaccharide fraction was precipitated with ethanol and referred to as UPEF. UPEF contains $36.10 \pm 3.20 \%$ fucoidan. An $80 \%$ ethanol extract of $E$. cava was prepared (ECE), and it contained $26.85 \pm 0.16 \%$ phenols. The sea squirt skin was hydrolyzed with Celluclast, and glycosaminoglycans (GAGs) were separated and purified; the purity of GAGs was 95\%. All samples were stored at $-20^{\circ} \mathrm{C}$ until use. The sample mixtures were prepared by mixing each component solution at the described ratios.

\section{Measurement of the inhibitory effects of UPEF, ECE, and GAGs and their mixtures on mushroom tyrosinase}

The inhibition of mushroom tyrosinase was measured as previously described (Heo et al. 2009; Kang et al. 2012). In brief, the $200-\mu \mathrm{L}$ assay mixture in a 96 -well microplate contained $40 \mu \mathrm{L}$ of 1.5 -mM L-tyrosine, $140 \mu \mathrm{L}$ of $50-\mathrm{mM}$ phosphate buffer ( $\mathrm{pH} 6.5), 10 \mu \mathrm{L}$ of aqueous mushroom tyrosinase (1000 units $/ \mathrm{mL})$, and $10 \mu \mathrm{L}$ of test solution. The assay mixture was incubated at $37^{\circ} \mathrm{C}$ for $12 \mathrm{~min}$ and then kept on ice for $5 \mathrm{~min}$ to stop the reaction. The amount of dopachrome in the reaction mixture was measured at $490 \mathrm{~nm}$ using a microplate reader (BioTek Synergy HT, BioTek Instruments, Winooski, VT, USA).

\section{Cell culture}

B16F10 mouse melanoma cells (ATCC ${ }^{\circ}$ CRL-6475 $5^{\text {tw }}$ ) were purchased from ATCC (American Type Culture Collection, Manassas, VA, USA) and grown in DMEM supplemented with $10 \%$ heat-inactivated FBS, $100 \mathrm{U} / \mathrm{mL}$ penicillin, and $100 \mu \mathrm{g} / \mathrm{mL}$ streptomycin. The cells were incubated in an atmosphere of 5\% $\mathrm{CO}_{2}$ at $37^{\circ} \mathrm{C}$ and were sub-cultured every 4 days. Cells for experiments were seeded at a concentration of $5 \times 10^{4}$ cells $/ \mathrm{mL}$.

\section{Cell viability assay}

Cell viability was quantified by a colorimetric MTT assay (Wang et al. 2017; Wang et al. 2018). Briefly, B16F10 cells were seeded in a 96-well plate and incubated for $24 \mathrm{~h}$. The cells were treated with different concentrations of test samples and incubated for $72 \mathrm{~h}$. MTT solution $(50 \mu \mathrm{L}, 2 \mathrm{mg} / \mathrm{mL})$ was added to each well and incubated for $3 \mathrm{~h}$. The supernatant was aspirated, $150 \mu \mathrm{L}$ of DMSO was added to each well, and the absorbance was measured at $540 \mathrm{~nm}$ using a microplate reader.

\section{Measurement of cellular melanin content}

B16F10 cells were seeded in a 6-well plate and incubated for $24 \mathrm{~h}$. The cells were treated with various concentrations of test samples and stimulated with $\alpha-\mathrm{MSH}$ $(50 \mathrm{nM})$. After $72 \mathrm{~h}$, the cells were washed with ice-cold PBS and harvested. The harvested cells were incubated at $80^{\circ} \mathrm{C}$ for $1 \mathrm{~h}$ in $1 \mathrm{~mL}$ of $1-\mathrm{N} \mathrm{NaOH}$ containing $10 \%$ DMSO. The absorbance of the supernatant was 
measured at $490 \mathrm{~nm}$ using a microplate reader (Heo et al. 2010).

\section{Western blot analysis}

The effect of the test samples on the expression of melanogenesis-related proteins including MITF, tyrosinase, TRP-1, and TRP-2 was assessed by Western blot analysis as described previously (Kim et al. 2013). In brief, B16F10 cells were incubated with various concentrations of the test sample and stimulated with $\alpha-\mathrm{MSH}(50 \mathrm{nM})$. After $72 \mathrm{~h}$, cells were harvested and lysed. The protein content of each sample was measured with a $\mathrm{BCA}^{\mathrm{mm}}$ kit. The proteins $(50 \mu \mathrm{g})$ were separated by SDS-PAGE and transferred onto nitrocellulose membranes. The membranes were incubated in blocking buffer ( $5 \%$ skim milk) and then with primary antibodies for $16 \mathrm{~h}$ at $4{ }^{\circ} \mathrm{C}$. The membranes were then incubated with secondary antibody at room temperature for 3 $h$. Finally, the proteins were visualized using an ECL Western blotting detection kit and exposure to X-ray film.

\section{Statistical analysis}

All experiments were performed in triplicate. The data were expressed as means \pm standard errors (S.E). The mean values of each experiment were compared using one-way ANOVA. Significant differences between the means were determined by the Duncan test. A $p$ value $<0.05$ was considered to be statistically significant, and degrees of significance were indicated as follows: ${ }^{*} p<0.05,{ }^{* * *} p<0.01$, **:* $p<0.001$, and ${ }^{\# \# \#} p<0.001$.

\section{Results}

Tyrosinase inhibition by UPEF, ECE, and GAGs

The effects of UPEF, ECE, and GAGs on tyrosinase activity were examined by measuring L-tyrosine hydroxylation. Arbutin was used as a positive control. As Fig. 1 shows, UPEF, ECE, and GAGs inhibited tyrosinase activity in a dose-dependent manner. ECE showed the strongest inhibition of the three agents, and it inhibited tyrosinase activity by $64.33 \%$ at a concentration of $100 \mu \mathrm{g} / \mathrm{mL}$.

\section{Cytotoxicity of UPEF, ECE, and GAGs on B16F10 cells}

The cytotoxicities of UPEF, ECE, and GAGs on B16F10 cells were examined by MTT assay, and the results are summarized in Fig. 2a. As the results show, ECE caused significant cytotoxicity in B16F10 cells. In addition, UPEF and GAGs were slightly toxic to B16F10 cells at high concentration $(100 \mu \mathrm{g} / \mathrm{mL})$.

\section{Effects of UPEF, ECE, and GAGs on melanin synthesis in a-} MSH-stimulated B16F10 cells

As Fig. 2b indicates, the melanin content of cells not stimulated with $\alpha-\mathrm{MSH}$ is referred to as $100 \%$, and the melanin content of cells stimulated with $\alpha-\mathrm{MSH}$ increased by $80 \%$. The melanin content of cells treated with UPEF, ECE, and GAGs decreased in a dose-dependent manner. These results indicated that all three test substances inhibited melanogenesis in $\alpha$ MSH-stimulated B16F10 cells, and ECE showed the strongest effect.

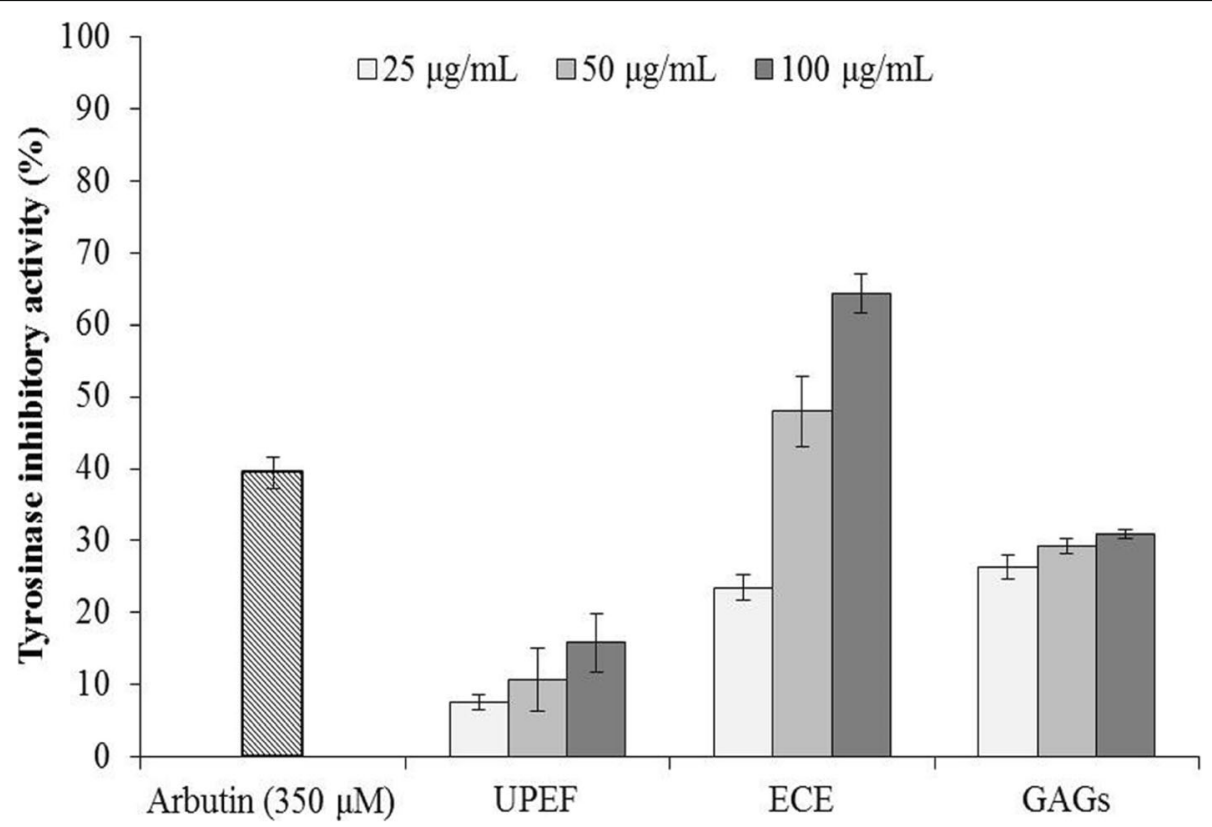

Fig. 1 Effect of UPEF, ECE, and GAGs on mushroom tyrosinase activity. Tyrosinase activity was measured by colorimetric assay. Dopachrome was measured at $490 \mathrm{~nm}$ using a microplate reader. The data are expressed as the means $\pm \mathrm{S}$. E $(n=3)$ 

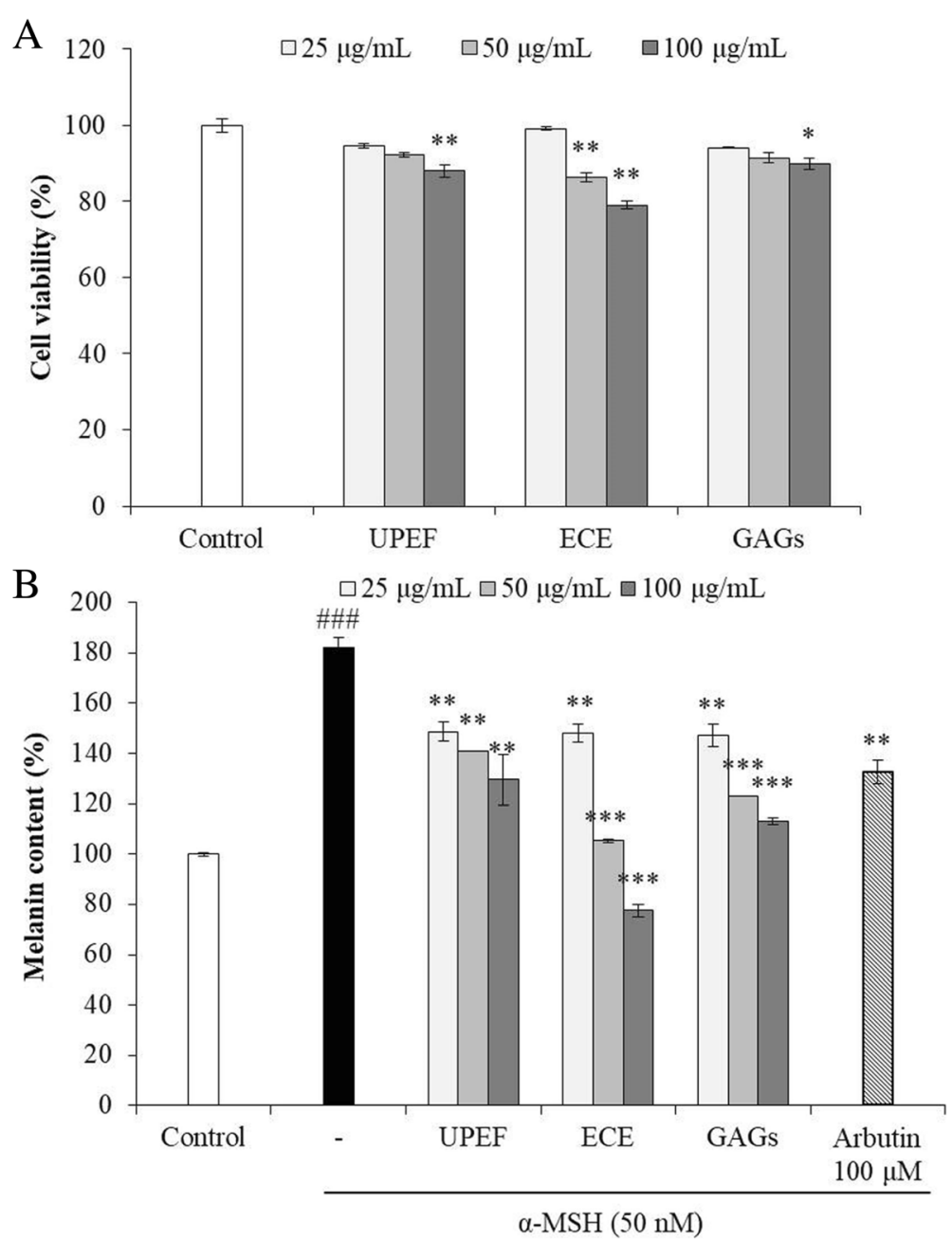

Fig. 2 Cytotoxicity and melanin synthesis in UPEF-, ECE-, and GAGs-treated B16F10 cells. a Cytotoxicity on B16F10 cells; b melanin synthesis in aMSH-stimulated B16F10 cells. The data are expressed as the means $\pm \mathrm{S}$. $\mathrm{E}(n=3) .{ }^{*} p<0.05,{ }^{* *} p<0.01$, and ${ }^{* * *} p<0.001$ as compared to the aMSH-treated group and ${ }^{\# \# \#} p<0.001$ as compared to the control group

Tyrosinase inhibition by combinations of UPEF, ECE, and GAGs

UPEF, ECE, and GAGs were combined in various ratios by volume, and the effect on tyrosinase activity was measured. As Fig. 3 shows, tyrosinase activity decreased as the ECE ratio in the mixture increased. In addition, the inhibitory activities of the test agents in combination were stronger compared to each agent alone at the same concentration.

\section{Cytotoxicity of UPEF, ECE, and GAGs in combination on B16F10 cells}

Using the tyrosinase inhibition conferred by the test agents in combination, seven combinations (UEG-262, UEG-271, UEG-352, UEG-361, UEG-433, UEG-451, and UEG-721) were selected to test the effects on melanogenesis in B16F10 cells. The cytotoxicities of these combinations in B16F10 cells were measured by MTT assay. As Fig. 4a shows, most combinations were slightly toxic to B16F10 cells, and UPEF to ECE to GAGs at 2:6:2 (UEG-262) showed the strongest cytotoxicity. On the other hand, UEG-451 showed no cytotoxicity in B16F10 cells.

Effect of test agents in combination on melanin synthesis in a-MSH-stimulated B16F10 cells

The effects of the test agents in combination on melanogenesis were assessed by measuring melanin synthesis in $\alpha$-MSH-stimulated B16F10 cells. As the results show (Fig. 4b), all combinations significantly reduced melanin synthesis in $\alpha-\mathrm{MSH}$-stimulated B16F10 cells, especially UEG-451. These results show that UPEF, ECE, and GAGs in combination inhibited melanogenesis, and 4:5: 1 is the optimum ratio. 


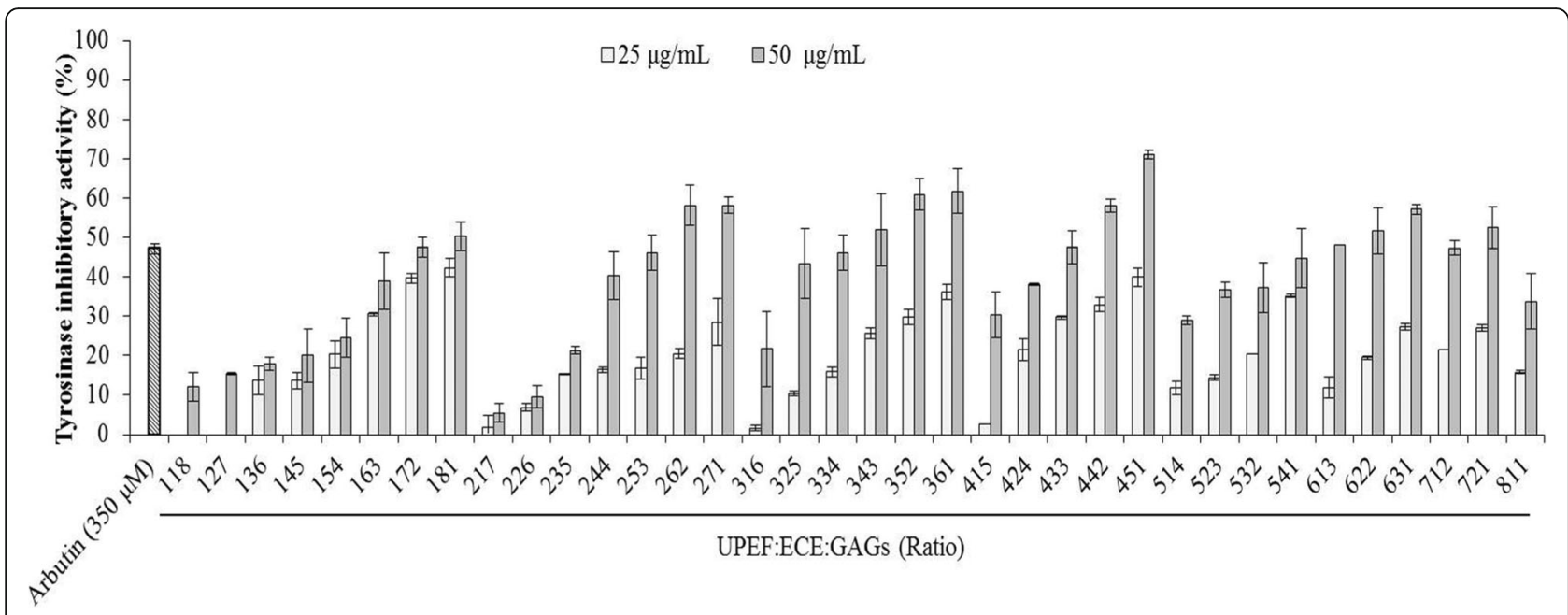

Fig. 3 The effects of UPEF, ECE, and GAGs in combination on mushroom tyrosinase activity. Tyrosinase activity was measured by colorimetric assay. Dopachrome was measured at $490 \mathrm{~nm}$ using a microplate reader. The data are expressed as the means $\pm \mathrm{S}$. E $(n=3)$
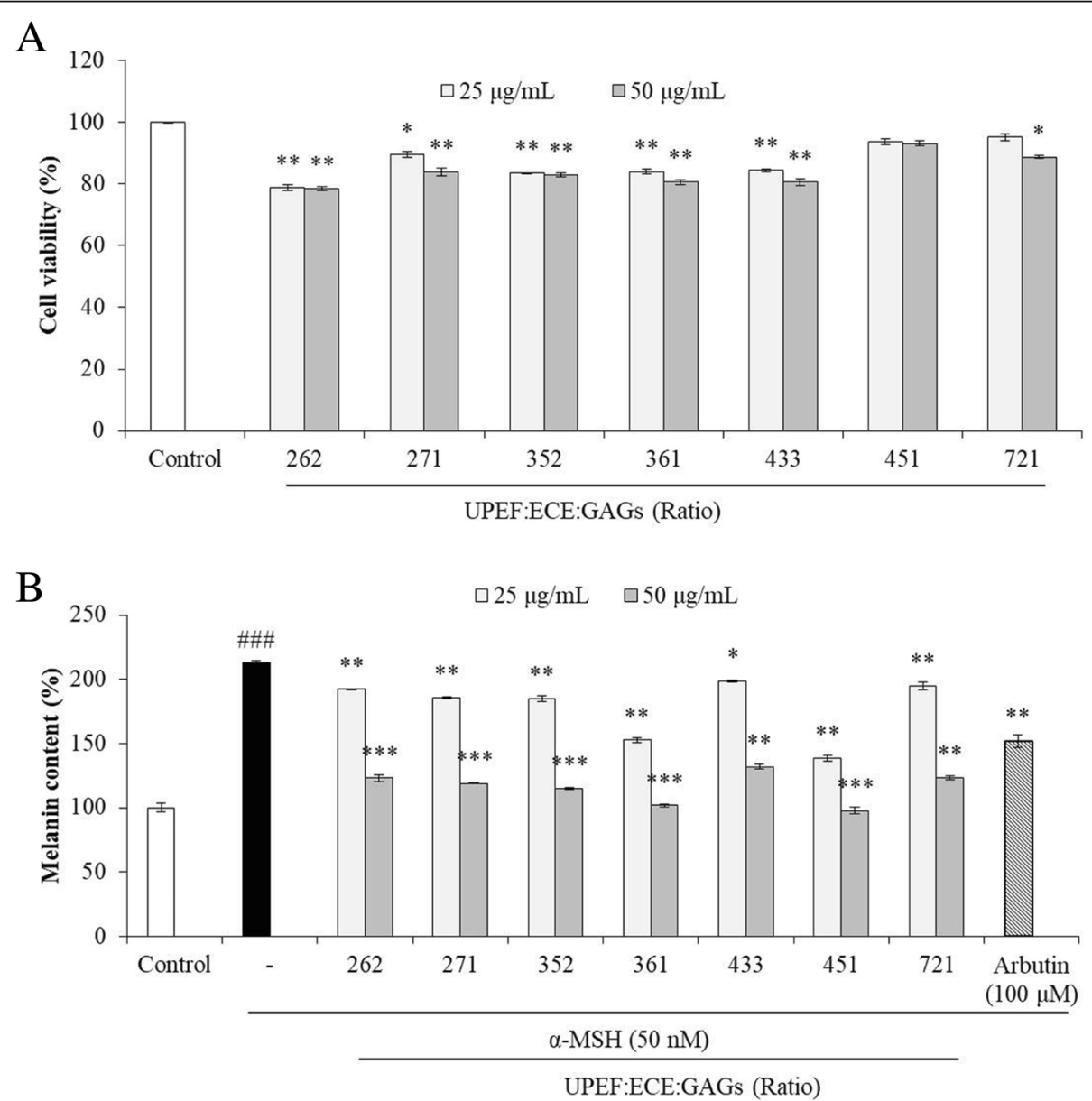

Fig. 4 Cytotoxicity and melanin synthesis in B16F10 cells treated with UPEF, ECE, and GAGs in combination. a Cytotoxicity on B16F10 cells; (b) melanin synthesis in a-MSH-stimulated B16F10 cells. The data are expressed as the means \pm S. E $(n=3) .{ }^{*} p<0.05,{ }^{* *} p<0.01$, and ${ }^{* * *} p<0.001$ as compared to the a-MSH-treated group and ${ }^{\# \# \# p} p 0.001$ as compared to the control group 

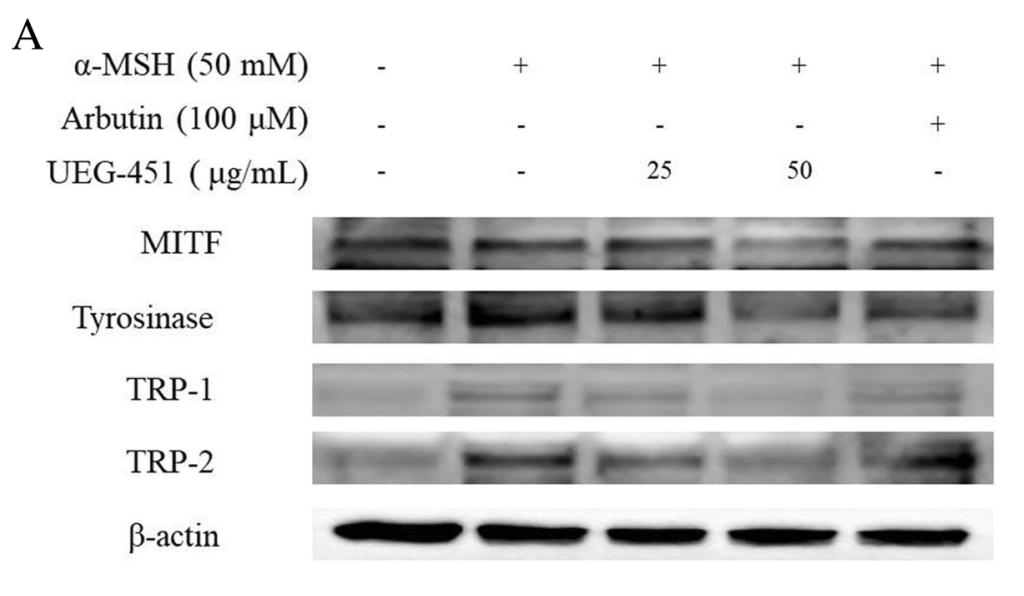

B

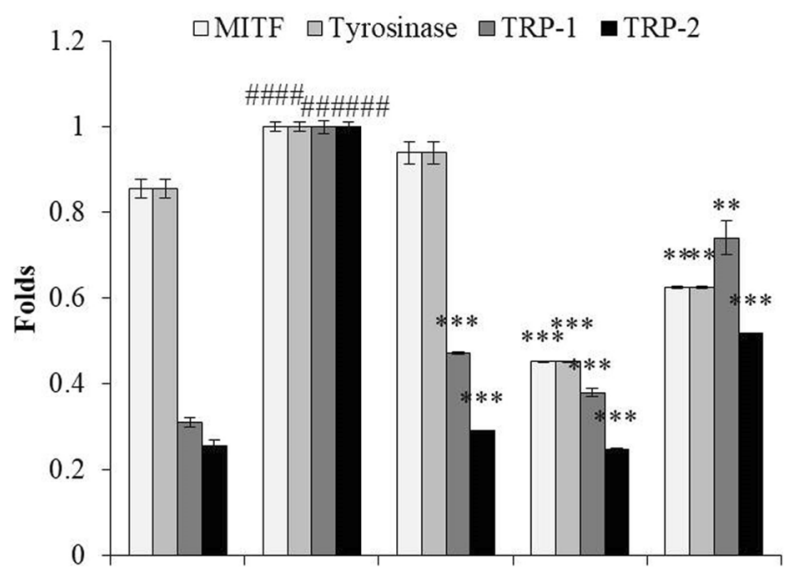

Fig. 5 Effect of UEG-451 on tyrosinase, TRP-1, TRP-2, and MITF expression in a-MSH-stimulated B16F10 cells. a The effect of UEG-451 on tyrosinase, TRP-1, TRP-2, and MITF expressions; (b) the relative amounts of tyrosinase, TRP-1, TRP-2, and MITF. The relative amounts of tyrosinase, TRP-1, TRP-2, and MITF were normalized to $\beta$-actin. The data are expressed as the means $\pm S$. E $(n=3) .{ }^{* *} p<0.01$ and ${ }^{* * *} p<0.001$ as compared to the a-MSH-treated group and ${ }^{\# \# \# ~} p<0.001$ as compared to the control group

Effect of UEG-451 on tyrosinase, TRP-1, TRP-2, and MITF expression in a-MSH-stimulated B16F10 cells

Based on its cytotoxicity and inhibition of melanogenesis, UEG-451 was selected for further research to evaluate the mechanisms of its anti-tyrosinase and anti-melanogenesis activities. The effect of UEG-451 on the expression of tyrosinase, TRP-1, TRP-2, and MITF was examined by Western blot analysis. As shown in Fig. 5, the expressions of tyrosinase, TRP-1, TRP-2, and MITF were increased by $\alpha-\mathrm{MSH}$ stimulation and the expressions of these proteins were reduced in cells pre-treated with different concentrations of UEG-451.

\section{Discussion}

In Asian cultures, lighter skin tones are considered more desirable. To meet the needs of the many women who suffer from hyperpigmentation, whitening agents have been developed for cosmetic and medical applications. Various whitening cosmetics or cosmeceuticals, which are made from natural or chemosynthetic materials, are commercially available. However, some of these materials possess side effects or are toxic because they contain substances such as hydroquinone and heavy metals. Thus, more research is devoted to searching for safe and effective whitening agents from natural sources.

Many studies have reported the effects of plant extracts or compounds isolated from plants on melanogenesis (Arung et al. 2011; Chan et al. 2011). Arung et al. (2011) isolated quercetin and its derivatives from Allium cepa and investigated their anti-melanogenesis effects (Arung et al. 2011). Chan et al. (2011) evaluated the tyrosinase inhibition and melanin synthesis inhibition in B16F10 cells of Sargassum polycystum ethanolic extracts and their fractions (Chan et al. 2011). In the present study, we evaluated melanogenesis inhibition conferred by a fucoidan-rich extract, a phlorotannin-rich extract, and GAGs obtained from seaweed and sea squirt, and investigated their whitening effects when in combination. 
The effects of UPEF, ECE, and GAGs on commercial mushroom tyrosinase were investigated, and the results indicated that all samples possess tyrosinase inhibitory activity with ECE showing the strongest activity of the three (Fig. 1). In addition, UPEF, ECE, and GAGs significantly reduced $\alpha-\mathrm{MSH}$-induced melanin synthesis in B16F10 cells in a dose-dependent manner (Fig. 2). ECE showed stronger melanin synthesis inhibition activity than UPEF and GAGs, and the melanin content of cells treated with $100 \mu \mathrm{g} / \mathrm{mL}$ of ECE was lower than the unstimulated cells. These results demonstrated that ECE is a potent inhibitor of melanin synthesis in $\alpha-\mathrm{MSH}$-stimulated and non-stimulated B16F10 cells. However, all three samples were cytotoxic to B16F10 cells, especially ECE. Therefore, we mixed the test agents in different ratios and compared the whitening effects and toxicities of the combinations to those of the agents alone.

The inhibition of tyrosinase and melanin synthesis conferred by the combinations was stronger than each single agent at the same concentrations (Fig. 1 and Fig. 3; Fig. $2 \mathrm{~b}$ and Fig. $4 \mathrm{~b}$ ); UEG-451 showed the strongest activity and no toxicity, with $71.10 \%$ of control tyrosinase activity and a $115.24 \%$ reduction in $\alpha-\mathrm{MSH}$-stimulated melanin synthesis at $50 \mu \mathrm{g} / \mathrm{mL}$. Combining the agents at an optimal ratio may be an ideal and effective way to improve bioactivity and reduce cytotoxicity.

Melanogenesis is regulated by enzymes including tyrosinase, TRP-1, and TRP-2. Tyrosinase is considered to be the rate-limiting enzyme of melanin biosynthesis and represents the major regulatory step in melanogenesis (Maeda et al. 1997). Thus, the inhibition of related enzymes is the most common approach to developing skin-whitening agents. The present results revealed that UEG-451 inhibited tyrosinase and reduced melanin synthesis in $\alpha-\mathrm{MSH}$-stimulated B16F10 cells. In addition, Western blot results demonstrated that the expressions of tyrosinase, TRP-1, and TRP-2 in UEG-451-treated cells decreased in a dose-dependent manner compared to non-treated cells (Fig. 5a and b). The tyrosinase family genes, TRP-1 and TRP-2, which are responsible for melanin synthesis, are regulated by MITF (Levy et al. 2006). As Fig. 5 shows, UEG- 451 at $50 \mu \mathrm{g} / \mathrm{mL}$ significantly reduced MITF expression in $\alpha$-MSH-stimulated B16F10 cells. These results suggest that UEG-451 inhibition of $\alpha-\mathrm{MSH}$-induced melanogenesis in B16F10 cells may be through the downregulation of tyrosinase, TRP1 , and TRP-2 via inhibition of MITF expression.

\section{Conclusions}

The present study investigated the inhibition of melanogenesis conferred by natural marine bio-resources including UPEF, ECE, and GAGs in $\alpha-\mathrm{MSH}$-stimulated B16F10 melanoma cells. The results indicated that all three agents inhibited tyrosinase and melanin synthesis in $\alpha-\mathrm{MSH}$-stimulated B16F10 cells and that they can act synergistically when in combination. In addition, UPEF, ECE, and GAGs in the ratio of 4:5:1 (UEG-451) showed the strongest activity and was not toxic. These results suggest UEG-451 may be an ideal whitening agent for use in the medical and cosmetic industries.

\section{Acknowledgements \\ The authors wish to thank the Ministry of Trade, Industry and Energy (MOTIE), and Korea Institute for Advancement of Technology (KIAT) for the support for this study.}

\section{Authors' contributions}

LW, JYK, and YJJ designed this study and wrote the manuscript. LW, YRC, HWY, and HGL performed the experiments and analyzed the data. LW and YRC contributed equally to this study. All authors read and approved the final manuscript.

\section{Funding}

This research is supported by "Rediscover of the Past R\&D Result" through the Ministry of Trade, Industry and Energy (MOTIE), and Korea Institute for Advancement of Technology (KIAT) (Grant No:: N0002151, Project: The commercialization of anti-aging products (Aquato Return 20).

Availability of data and materials

All data sets generated and analyzed during the current study are available from the corresponding author on reasonable request.

Ethics approval and consent to participate

Not applicable.

Consent for publication

Not applicable.

\section{Competing interests}

The authors declare that they have no competing interests.

Received: 9 April 2019 Accepted: 17 May 2019

Published online: 31 May 2019

\section{References}

Ahn G-N, Kim K-N, Cha S-H, Song C-B, Lee J, Heo M-S, Yeo I-K, Lee N-H, Jee Y-H, Kim J-S. Antioxidant activities of phlorotannins purified from Ecklonia cava on free radical scavenging using ESR and $\mathrm{H} 2 \mathrm{O} 2$-mediated DNA damage. Eur Food Res Technol. 2007;226:71-9.

Arung ET, Furuta S, Ishikawa H, Kusuma IW, Shimizu K, Kondo R. Antimelanogenesis properties of quercetin-and its derivative-rich extract from Allium cepa. Food Chem. 2011;124:1024-8.

Campo GM, Avenoso A, Campo S, D'Ascola A, Ferlazzo AM, Calatroni A. The antioxidant and antifibrogenic effects of the glycosaminoglycans hyaluronic acid and chondroitin-4-sulphate in a subchronic rat model of carbon tetrachloride-induced liver fibrogenesis. Chem Biol Interact. 2004;148:125-38.

Chan Y, Kim K, Cheah S. Inhibitory effects of Sargassum polycystum on tyrosinase activity and melanin formation in B16F10 murine melanoma cells. J Ethnopharmacol. 2011:137:1183-8.

Fernando I, Kim H-S, Sanjeewa K, Oh J-Y, Jeon Y-J, Lee WW. Inhibition of inflammatory responses elicited by urban fine dust particles in keratinocytes and macrophages by diphlorethohydroxycarmalol isolated from a brown alga Ishige okamurae. Algae. 2017;32:261-73.

Gilchrest BA, Eller MS. DNA photodamage stimulates melanogenesis and other photoprotective responses. J Investig Dermatol Symp Proc. 1999;4:35-40.

Heo S-J, Ko S-C, Cha S-H, Kang D-H, Park H-S, Choi Y-U, Kim D, Jung W-K, Jeon Y$J$. Effect of phlorotannins isolated from Ecklonia cava on melanogenesis and their protective effect against photo-oxidative stress induced by UV-B radiation. Toxicol in Vitro. 2009;23:1123-30.

Heo S-J, Ko S-C, Kang S-M, Cha S-H, Lee S-H, Kang D-H, Jung W-K, Affan A, Oh C, Jeon Y-J. Inhibitory effect of diphlorethohydroxycarmalol on melanogenesis 
and its protective effect against UV-B radiation-induced cell damage. Food Chem Toxicol. 2010;48:1355-61.

Kang M-C, Kim S-Y, Kim E-A, Lee J-H, Kim Y-S, Yu S-K, Chae JB, Choe I-H, Cho JH, Jeon Y-J. Antioxidant activity of polysaccharide purified from Acanthopanax koreanum Nakai stems in vitro and in vivo zebrafish model. Carbohyd Polym. 2015;127:38-46.

Kang M-C, Wijesinghe WAJP, Lee S-H, Kang S-M, Ko S-C, Yang X, Kang N, Jeon BT, Kim J, Lee D-H, Jeon Y-J. Dieckol isolated from brown seaweed Ecklonia cava attenuates type II diabetes in db/db mouse model. Food Chem Toxicol. 2013:53:294-8.

Kang S-M, Heo S-J, Kim K-N, Lee S-H, Yang H-M, Kim A-D, Jeon Y-J. Molecular docking studies of a phlorotannin, dieckol isolated from Ecklonia cava with tyrosinase inhibitory activity. Bioorg Med Chem. 2012;20:311-6.

Kijjoa A, Sawangwong P. Drugs and cosmetics from the sea. Marine Drugs. 2004; 2:73-82

Kim H-H, Kim H-S, Ko J-Y, Kim C-Y, Lee J-H, Jeon Y-J. A single-step isolation of useful antioxidant compounds from Ishige okamurae by using centrifugal partition chromatography. Fish Aquat Sci. 2016;19:22.

Kim H-S, Zhang C, Lee J-H, Ko J-Y, Kim E-A, Kang N, Jeon Y-J. Evaluation of the biological activities of marine bacteria collected from Jeju Island, Korea, and isolation of active compounds from their secondary metabolites. Fish Aquat Sci. 2014;17:215-22.

Kim K-N, Yang H-M, Kang S-M, Kim D, Ahn G, Jeon Y-J. Octaphlorethol A isolated from Ishige foliacea inhibits a-MSH-stimulated induced melanogenesis via ERK pathway in B16F10 melanoma cells. Food Chem Toxicol. 2013;59:521-6.

Ko J-Y, Kang N, Lee J-H, Kim J-S, Kim W-S, Park S-J, Kim Y-T, Jeon Y-J. Angiotensin I-converting enzyme inhibitory peptides from an enzymatic hydrolysate of flounder fish (Paralichthys olivaceus) muscle as a potent anti-hypertensive agent. Process Biochem. 2016;51:535-41.

Ko S-C, Kang MC, Kang N, Kim H-S, Lee S-H, Ahn G, Jung W-K, Jeon Y-J. Effect of angiotensin I-converting enzyme (ACE) inhibition and nitric oxide (NO) production of 6,6'-bieckol, a marine algal polyphenol and its anti-hypertensive effect in spontaneously hypertensive rats. Process Biochem. 2017;58:326-32.

Lange KW, Hauser J, Nakamura Y, Kanaya S. Dietary seaweeds and obesity. Food Sci Human Wellness. 2015;4:87-96.

Lee J-H, Ko J-Y, Samarakoon K, Oh J-Y, Heo S-J, Kim C-Y, Nah J-W, Jang M-K, Lee $J$ JS, Jeon Y-J. Preparative isolation of sargachromanol E from Sargassum siliquastrum by centrifugal partition chromatography and its antiinflammatory activity. Food Chem Toxicol. 2013;62:54-60.

Lee J-H, Zhang C, Ko J-Y, Lee J-S, Jeon Y-J. Evaluation on anticancer effect against $\mathrm{HL}-60$ cells and toxicity in vitro and in vivo of the phenethyl acetate isolated from a marine bacterium Streptomyces griseus. Fish Aquat Sci. 2015;18:35-44.

Levy C, Khaled M, Fisher DE. MITF: master regulator of melanocyte development and melanoma oncogene. Trends Mol Med. 2006;12:406-14.

Maeda K, Yokokawa Y, Hatao M, Naganuma M, Tomita Y. Comparison of the melanogenesis in human black and light brown melanocytes. J Dermatol Sci. 1997:14:199-206.

Oh J-Y, Fernando IS, Jeon Y-J. Potential applications of radioprotective phytochemicals from marine algae. Algae. 2016;31:403-14.

Park E-J, Choi J-i. Melanogenesis inhibitory effect of low molecular weight fucoidan from Undaria pinnatifida. J Appl Physiol. 2017;29:2213-7.

Samarakoon KW, Ko J-Y, Lee J-H, Kwon ON, Kim S-W, Jeon Y-J. Apoptotic anticancer activity of a novel fatty alcohol ester isolated from cultured marine diatom, Phaeodactylum tricornutum. J Funct Foods. 2014;6:231-40.

Sanjeewa KKA, Fernando IPS, Samarakoon KW, Lakmal HHC, Kim E-A, Kwon O-N, Dilshara MG, Lee J-B, Jeon Y-J. Anti-inflammatory and anti-cancer activities of sterol rich fraction of cultured marine microalga Nannochloropsis oculata. Algae. 2016;31:277-87.

Tengamnuay P, Pengrungruangwong K, Pheansri I, Likhitwitayawuid K. Artocarpus lakoocha heartwood extract as a novel cosmetic ingredient: evaluation of the in vitro anti-tyrosinase and in vivo skin whitening activities. Int J Cosmet Sci. 2006;28:269-76

Wang L, Fernando IS, Kim E-a, Jeon Y-j. Soft corals collected from Jeju Island; a potential source of anti-inflammatory phytochemicals. J Chitin Chitosan. 2016;21:247-54.

Wang L, Jo M-J, Katagiri R, Harata K, Ohta M, Ogawa A, Kamegai M, Ishida Y, Tanoue S, Kimura S, Lee S-C, Jeon Y-J. Antioxidant effects of citrus pomace extracts processed by super-heated steam. LWT. 2018;90:331-8.

Wang L, Ryu B, Kim W-S, Kim GH, Jeon Y-J. Protective effect of gallic acid derivatives from the freshwater green alga Spirogyra sp. against ultraviolet Binduced apoptosis through reactive oxygen species clearance in human keratinocytes and zebrafish. Algae. 2017;32:379-88.

\section{Publisher's Note}

Springer Nature remains neutral with regard to jurisdictional claims in published maps and institutional affiliations.
Ready to submit your research? Choose BMC and benefit from:

- fast, convenient online submission

- thorough peer review by experienced researchers in your field

- rapid publication on acceptance

- support for research data, including large and complex data types

- gold Open Access which fosters wider collaboration and increased citations

- maximum visibility for your research: over $100 \mathrm{M}$ website views per year

At BMC, research is always in progress.

Learn more biomedcentral.com/submissions 